\title{
Asymptomatic hyponatremic hypochloremic metabolic alkalosis: An unusual initial presentation of Cystic Fibrosis in an infant
}

\author{
Upma Suneja $^{1}$, Akhila Mandadi ${ }^{2}$, Lil Rodriguez $^{3}$, George Vermenton ${ }^{3}$ and Jayendra Sharma ${ }^{3}$ \\ ${ }^{1}$ Pediatric Gastroenterology Department, Children Hospital, Oklahoma University Health Science Center, Oklahoma City, Oklahoma, USA \\ ${ }^{2}$ Pediatric Emergency Medicine Department, University of Florida College of Medicine, Jacksonville, Florida, USA \\ ${ }^{3}$ Pediatrics Department, Lincoln Medical Center, Affiliated with Weill Cornell Medical College, New York, USA
}

\section{Introduction}

Cystic fibrosis is an inherited channelopathy caused by mutation in the gene coding for transmembrane conductance regulator protein resulting in multiple manifestations. Newborn screening has been very helpful in early detection of cystic fibrosis cases and prevention of complications. Failure to thrive is known to be the most common and earliest manifestation of cystic fibrosis in infants diagnosed with newborn screening [1]. Here, we present the case of a 35 day old male infant, diagnosed with cystic fibrosis by newborn screening who presented with hyponatremic metabolic alkalosis in the absence of any other symptoms.

\section{Case}

This is a 35 days old male infant born at term, adequate for gestational age without any perinatal complications. The newborn screen was reported to be positive for cystic fibrosis and the patient was referred to outside hospital where sweat chloride test on 2 separate occasions was 57 and $60 \mathrm{mMol} / \mathrm{L}$. Due to some insurance issues, the patient was sent back to our hospital for further work up. Meanwhile, the patient was noted to be growing and developing well. Labs done in pediatric clinic were significant for hyponatremic $(115 \mathrm{mEq} / \mathrm{L})$, hypochloremic (69 mEq/L) Alkalosis (CO2: 34). CFTR full gene analysis was also sent. Due to the lab abnormalities, the patient was immediately referred to pediatrics Emergency department where the labs were repeated. Repeat labs resulted with Sodium: $114 \mathrm{mEq} / \mathrm{L}$, Potassium: $4.1 \mathrm{mEq} / \mathrm{L}$, chloride: $71 \mathrm{mEq} / \mathrm{L}$ along with alkalosis $(\mathrm{CO} 2$ : 28). In a detailed interview, mother stated that the patient was feeding well with breastfeeding every 2 hours with supplemental 1-2 bottles of formula every day. He was passing soft stools and denied any fever, diarrhea or respiratory symptoms. Mother reported that he is always very hungry and that his sweat tastes very salty. Family history was positive for distant male cousin with confirmed diagnosis of cystic fibrosis. Of note is that this presentation was in the month of March. Physical exam was remarkable for active child, breathing comfortably on room air, soft abdomen, good muscle tone and capillary refill of $<2$ seconds. In the Emergency department, patient received one bolus of $0.33 \% \mathrm{NaCl}$ and was referred for admission to the pediatric intensive care unit for electrolyte replenishment. In the intensive care unit, the patient was treated initially with intravenous hypertonic saline (3\%) under close monitoring with gradual improvement in electrolytes (Sodium: $128 \mathrm{mEq} / \mathrm{L}$ and Chloride: $92 \mathrm{mEq} / \mathrm{L}$ ). At this time, the intravenous hypertonic saline was switched to oral Sodium chloride supplement along with ongoing breast and formula feeding. CFTR gene analysis reported c.254G >A (p.G85E) and c.1826A > G (p.H609R) alteration which are pathogenic mutations consistent with cystic fibrosis. During the hospitalization, the patient was gaining weight and no new symptoms were reported. At the time of discharge, the electrolytes were within normal limits and a follow up appointment was made.

\section{Discussion}

Cystic fibrosis is a multisystem disorder known to present mostly with pulmonary and gastrointestinal manifestations. Traditionally, sweat chloride test has been used to diagnose the patients with cystic fibrosis. Newborn screening definitely has helped in early identification and management of these patients. The classic picture of a cystic fibrosis patient is defined by growth retardation, chronic pulmonary complications, pancreatic insufficiency and electrolyte abnormalities. A review of clinical records of patient diagnosed with cystic fibrosis from 1985 to 2004 showed that $16.8 \%$ of the patients presented with metabolic alkalosis and electrolyte depletion. Of note, the age of the infants ranged from 3 to 14 months and all the episodes occurred in summer months with some of them having acute infectious illness [2]. A 9 year old boy, diagnosed with cystic fibrosis by new born screening was reported to have episodic seasonal pseudo- barter syndrome like picture during summer months [3]. Infants with cystic fibrosis are at risk of developing hyponatremia particularly in high ambient temperatures or in the times of acute illnesses resulting in more losses. Salt supplementation is definitely a challenge in breast fed or formula fed infants [4].

\section{Conclusion}

Cystic fibrosis is a well-known condition with varied presentation affecting the overall health of the patients. Newborn screening has proved to be very helpful in early diagnosis and intervention resulting in improved quality of life for these patients. At 35 days

${ }^{*}$ Correspondence to: Upma Suneja, Pediatrics Gastroenterology fellow Children Hospital, Oklahoma University health Science Center, Oklahoma city, Oklahoma, E-mail: drupmasuneja@yahoo.com

Received: October 19, 2018; Accepted: October 27, 2018; Published: October 30, 2018 
age, our patient is the youngest cystic fibrosis patient to present with electrolyte abnormalities in the absence of any ongoing illness or weather changes. Through this case, we would like to emphasize the importance of considering cystic fibrosis as one of the differentials for hyponatremic alkalosis. Also, there seems to be a need for regularly screening these patients with established cystic fibrosis diagnosis for electrolyte abnormalities starting in early infancy even in the absence of any precipitating factors $[5,6]$.

\section{References}

1. Farahmand F, Khalili M, Shahbaznejad L, Hirbod-Mobarakeh A, Najafi Sani M, et al. (2013) Clinical presentation of cystic fibrosis at the time of diagnosis: a multicenter study in a region without newborn screening. Turk J Gastroenterol 24: 541-545. [Crossref]
2. Ballestero Y, Hernandez MI, Rojo P, Manzanares J, Nebreda V, et al. (2006) Hyponatremic dehydration as a presentation of cystic fibrosis. Pediatr Emerg Care 22: 725-7. [Crossref]

3. Kintu B1, Brightwell A (2014) Episodic seasonal pseudo- barter syndrome in cystic fibrosis. Paediatr Respir Rev 155: 19-21. [Crossref]

4. Guimarães EV1, Schettino GC, Camargos PA, Penna FJ (2012) Prevalence of hyponatremia at diagnosis and factors associated with the longitudinal variation in serum sodium levels in infants with cystic fibrosis. J Pediatr 161: 285-9. [Crossref]

5. Accurso FJ, Sontag MK, Wagener JS (2005) Complications associated with symptomatic diagnosis in infants with cystic fibrosis. J Pediatr 147: S37-S41. [Crossref]

6. Gilchrist FJ, Samuels M, Klafkowski G, Watson NA, Lenney W (2013) Pneumomediastinum and hyponatremic dehydration as presenting features of cystic fibrosis. Eur Respir J 42: 1760- 1762. [Crossref]

Copyright: $\odot 2018$ Suneja U. This is an open-access article distributed under the terms of the Creative Commons Attribution License, which permits unrestricted use, distribution, and reproduction in any medium, provided the original author and source are credited. 